\title{
Improvement of organization of ecological housing construction in the Moscow region
}

\author{
Arkady Larionov ${ }^{1 *}$ and Tatiana Nekrasova ${ }^{2}$ \\ ${ }^{1}$ Moscow State University of Civil Engineering, 109377, Moscow, Russia \\ ${ }^{2}$ Dmitrov Fisheries Technological Institute, village Rybnoye, 141821, Moscow region, Russia
}

\begin{abstract}
The paper substantiates that the development of ecological construction in Russia is currently progressing at an insufficiently high rate, which is primarily due to the lack of effective systemic support from the state at the legislative and executive levels. The author emphasizes that without the formation of a proper legislative base and state programs that stimulate ecological construction, all attempts to build by introducing innovative ecological solutions will not give the expected effect. The need for state incentives for business entities in the residential real estate market, the creation of legal and economic mechanisms that will be the engine of ecological housing construction in modern Russia is argued as a development perspective for the segment of the national economy studied in the work.
\end{abstract}

\section{Introduction}

The attempts carried out in recent years to comprehend the variety of types of human economic activity and its anthropogenic impact on the health of the entire population naturally lead scholars to the need to develop innovative methods and forms of organization of branches of the real sector of national economies, which should be based on modern systemic concepts and an integrated approach.

In addition, in the process of ongoing globalization and increasing competition between major players in the construction market, the agenda of sustainable socio-economic development of the leading countries of the world economic system dictates the need to adequately protect the domestic Russian market from the expansion of Western construction companies. The strongest competitive advantage of most of which over our domestic developers is the focus on the greening of the housing sector (both in terms of internal environmental factors and the desire to preserve the landscape of residential buildings at the end of the construction of residential real estate).

That is why the most effective and promising steps in this area should be considered the improvement of the Russian practice of housing construction, specifically, the introduction of innovative methods and forms of organization of ecological housing construction in it

\footnotetext{
${ }^{*}$ Corresponding author: tanyak186@mail.ru
} 
within the framework of the concept of the ecological and economic system "construction living environment".

\section{Methods}

The natural resources management and, more broadly, environmental management in the construction sector is a social activity, the systemic representation of which presupposes a theoretical substantiation of the genesis, composition and structure of the system; identification of the backbone determinant; diagnostics of interconnections and tendencies of sustainable development; identification of the target function; development of a management mechanism for the ecological and economic system.

The main difficulty in conducting scientific research of the ecological and economic system "construction - living environment" is the implementation of a multidisciplinary approach, which requires the study and understanding of methods of analysis and results obtained from various fields of science and economic practice. A modern civil scientist must think through, understand and operate with the concepts, categories and scientific results of technology and organization of construction production, investment and construction activities, geology, reinforced concrete, metal and wooden structures, geodesy, construction physics, industry economics, materials science, environmental protection, structural mechanics, chemistry, etc. Of course, it is not easy, but with old views of the Universe, it is useless and futile to build a New World. Because under the new conditions, traditional general scientific approaches and standard methods of conducting scientific research do not allow obtaining an increment of Knowledge necessary to improve economic practice.

If we assume that the ecological and economic system "construction - living environment" is quasi-static, then its properties will be similar for any evolutionary changes in states in time relative to the selected reference state. Hence, we can conclude that there is an index of the system I, which can be represented as a function of independent variables $\mathrm{xS}$, and is a function of the process. In this case, the quantity $\mathrm{I}=\mathrm{I}\left(\mathrm{x} \_1, \mathrm{x} \_2, \ldots, \mathrm{x} \_\mathrm{S}\right)$ determines the equation of state of the system in coordinates $\mathrm{x} \_1, \mathrm{x} \_2, \ldots, \mathrm{x} \_\mathrm{S}$.

Based on these assumptions and the first postulate of system dynamics [1], the absolute index of the system in the multidimensional space of variables will have the form of a homogeneous function of degree $q$ satisfying the Euler formula:

$$
I=\frac{1}{q}\left(x_{1} \frac{d I}{d x_{1}}+x_{2} \frac{d I}{d x_{2}}+\cdots+x_{n} \frac{d I}{d x_{n}}\right)
$$

This equation determines the relationship between the assessment of the quality of the system, its properties and possible impact in the vicinity of any state of the system in the implementation of processes that can be realized. At the same time, the question of the objectivity, correctness and information content of indicators and indices in the description of development processes, system relationships and the behavior of the system as a whole remains open, there are no actual methodological developments and prerequisites for the formation of a complex of indicators.

The basic list of indicators for environmental assessment of macrosystems was developed by the UN European Environmental Commission and is used in practice in assessing the development of the EU countries [8, 14 and others]. Indicators are formed in the following areas: socio-economic development, public health, quality of atmospheric air and surface water, climate change, the impact of economic sectors on the environment, etc.

A number of international methods use a complex of ten or more different indicators to assess the development of countries or regions. For example, when assessing the environmental development of countries, about 70 indicators can be used, combined into 14 
groups, which comprehensively characterize the socio-economic and environmental situation in European countries [2, 3, etc.].

In turn, the well-known Russian methodology for assessing the ecological state of a territory [3] uses 45 indicators to assess changes in the habitat, health status of the population, assess the disturbance of the natural environment, degradation of terrestrial ecosystems, biogeochemical assessment of the territory, etc.

The existing system of organizational, technical and economic relations between nature and society assumes, in the complex of objects of study, to consider categories that have the property of consumption, utility, value and have a limited character. This approach allows the use of the category "system services" - this is the profit or benefits that people receive from the system "construction - living environment". Among them, one can single out: providing services are useful real estate, direct system products; related services are the benefits obtained from the formation of system processes, intangible benefits in the form of living conditions and business; supporting services are services needed to support all other system services, such as building social infrastructure.

The main form and method of the influence of the subject of housing construction on the environment is construction products characterized by such categories as "quality""price"-“competitiveness", which partially translates the research task into the plane of currently relevant social marketing. The category "real estate" systemically drifts from a commodity and develops into a global factor of the flow of influence, which activates the vector "output parameters of construction - characteristics of the environment" and implements the coupling of subsystems. In turn, the surrounding natural environment is able to change the quality of the construction subject interacting with it through input resources or feedback.

The second area of the analytical approach includes factors of the external and internal environment, directly or indirectly reflecting the integral quality of the living environment and business. These include the welfare of the population; the quality of the social sphere; the quality of the environment (internal factors include the environmental friendliness of the technologies, materials, structures used; electromagnetic radiation; noise; air conditioning; quality of water for household needs and drinking; radioactivity of the materials and structures used; external factors include - remoteness from major highways, waste incineration and waste processing plants, industrial enterprises, etc.); the quality of the business environment.

To assess the complex property "environmental friendliness of structural elements", according to the author $[4,5]$, the values can be equal to $0 ; 0.25 ; 0.5$ and 1 , for the property "water supply system" - $0 ; 0.5$ and 1 . This gradation is caused by the fact that these properties consist of several simple single properties (Table 1).

Table1. Scale of quality criteria for assessing the environmental friendliness of a residential building

\begin{tabular}{|c|c|l|}
\hline Variable name & $\begin{array}{c}\text { Possible } \\
\text { value }\end{array}$ & \multicolumn{1}{c|}{ Qualitative criterion for assigning value } \\
\hline & 0 & $\begin{array}{l}\text { 1) the shape of the building does not correspond to the } \\
\text { shapes that are in harmony with the roadside environment } \\
\text { 2) the building material is not environmentally friendly } \\
\text { 3) the interior decoration material is not environmentally } \\
\text { friendly }\end{array}$ \\
\cline { 2 - 3 } \begin{tabular}{c} 
environmental $\begin{array}{c}\text { friendliness of } \\
\text { structural elements } \mathrm{x} 1\end{array}$ \\
\cline { 2 - 3 }
\end{tabular} & $\begin{array}{l}\text { 1) the shape of the building does not match the shapes } \\
\text { that are in harmony with the natural environment } \\
\text { 2) the building material or interior decoration material is } \\
\text { not environmentally friendly }\end{array}$ \\
\cline { 2 - 3 } & 0.25 & $\begin{array}{l}\text { 1) the shape of the building does not correspond to the } \\
\text { forms that are in harmony with the natural environment, } \\
\text { or }\end{array}$ \\
\hline
\end{tabular}




\begin{tabular}{|c|c|c|}
\hline & & $\begin{array}{l}\text { 2)the material of the building and the interior decoration } \\
\text { material are not environmentally friendly }\end{array}$ \\
\hline & 1 & $\begin{array}{l}\text { 1) the shape of the building corresponds to the forms in } \\
\text { harmony with the natural environment } \\
\text { 2) the material of the structure is environmentally } \\
\text { friendly } \\
\text { 3) interior decoration material is environmentally friendly }\end{array}$ \\
\hline environmental & 0 & $\begin{array}{l}\text { 1) use of groundwater } \\
\text { 2) simple consumption cycle }\end{array}$ \\
\hline $\begin{array}{l}\text { friendliness of the water } \\
\text { supply system }\end{array}$ & 0.5 & $\begin{array}{l}\text { 1) use of groundwater } \\
\text { or 2) simple consumption cycle }\end{array}$ \\
\hline $\mathrm{x} 2$ & 1 & $\begin{array}{l}\text { 1) use of natural precipitation with a filtration system } \\
\text { 2) recycling (multiple use of water with a filtration } \\
\text { system) }\end{array}$ \\
\hline $\begin{array}{l}\text { environmental } \\
\text { friendliness of the }\end{array}$ & 0 & $\begin{array}{l}\text { use of non-renewable sources or sources with a long } \\
\text { renewal period }\end{array}$ \\
\hline power supply system x3 & 1 & use of renewable energy sources \\
\hline $\begin{array}{l}\text { environmental } \\
\text { friendliness of the }\end{array}$ & 0 & no waste treatment process \\
\hline $\begin{array}{l}\text { sewerage system. } \\
\qquad 44\end{array}$ & 1 & biological waste treatment (composting) \\
\hline $\begin{array}{l}\text { environmental } \\
\text { friendliness of the solid }\end{array}$ & 0 & $\begin{array}{l}\text { lack of premises for primary processing, separate } \\
\text { collection and safe storage of garbage before delivery }\end{array}$ \\
\hline $\begin{array}{l}\text { waste collection system } \\
\qquad x_{5}\end{array}$ & 1 & $\begin{array}{l}\text { availability of premises for primary processing, separate } \\
\text { collection and safe storage of garbage before delivery }\end{array}$ \\
\hline $\begin{array}{l}\text { environmental } \\
\text { friendliness of the }\end{array}$ & 0 & $\begin{array}{l}\text { use of non-renewable sources or sources with a long } \\
\text { renewal period }\end{array}$ \\
\hline heating $\mathrm{s}$ & 1 & use of renewable energy sources \\
\hline $\begin{array}{l}\text { environmental } \\
\text { friendliness of the }\end{array}$ & 0 & $\begin{array}{l}\text { without the possibility of heat recovery (supply or } \\
\text { exhaust ventilation) }\end{array}$ \\
\hline ventilation s & 1 & heat recovery \\
\hline
\end{tabular}

From the standpoint of the scientific approach, the dominant of which is the life cycle, the deferred environmental and economic impact of construction on the living environment and business is associated with the impact on the nature of objects that are the products of construction - buildings, structures and their complexes, highways, bridges, solid waste landfills and other structures, urbanized areas in general. During the construction and operation of objects for various purposes, relief changes, violation of surface runoff parameters and hydrogeological conditions, an increase or decrease in the level of groundwater, a change in their chemical composition, movement of areas of recharge and discharge of groundwater occur. Changes in the state and properties of soils occur as a result of the transfer of loads from structures, contamination of soils with various substances fromplant emissions (discharges), moistening or dehydration, thermal effects. These changes lead to a decrease in the strength characteristics of soils, require special measures to stabilize and strengthen the bases and foundations of structures.

\section{Results}


Integrally, the quality of the living environment and business is defined as the degree of satisfaction of a certain basic set of needs of the subjects of the environment, characterized by the measure of development of various spheres of society. This measure is a rather complex characteristic, which, in turn, consists of a large number of indicators of different nature, which complicates their integral assessment. The approximate list of statistical indicators of the socio-economic situation of municipalities, approved by the Resolution of the State Statistics Committee of Russia, contains more than 190 groups of indicators and primary data. At the same time, the synthetic approach from a system-wide standpoint is integrally implemented through a set of goals of the socio-economic system.

Urban areas differ significantly from their natural surroundings. Their relief is leveled as a result of optimizing the slopes of the surfaces and as a result of increasing the cultural layer. The height and arrangement of buildings and structures determine the distribution of air masses and their condition. Installation of foundations, underground urbanism, water intake for water consumption, regulation of rivers and reservoirs within the city and adjacent areas, development and engineering improvement of territories, including the organization of surface runoff, all this completely changes the water regime of urbanized territories, leading to a sharp reduction in infiltration.

For Moscow, such a decrease will be $30 \%$. The vegetation cover of urban areas is sharply reducing and changing. In the urbanized area, water and soil are polluted as a result of industrial emissions, accumulation of municipal waste. Dustiness, gas and thermal air pollution, changes in the level of radiation and relative humidity, air temperatures, and wind conditions occur. New conditions, different from natural ones, are created on the urbanized territory.

For example, the territory of Moscow should be considered as an ecosystem of naturalanthropogenic type that exists under constant external influence of man and is intensively exploited by him.

The research results of V.P. Knyazeva [6] testify that the consequence of irrational nature management was the absence of an ecological reserve in certain municipal districts and, hence, the restriction of new construction in these territories. In such areas, builders face environmental problems. The quality of construction directly depends on the correct formulation and solution of environmental objectives and the constant assessment of environmental impacts at all stages of the project life cycle. In certain areas of the city,the intensity and variety of these impacts have already exceeded the rates of adaptation and stability of natural systems in many ways. This resulted in critical situations in the technosphere of the city, caused by the process of degradation of the natural environment.

The practical rating of the attractiveness of districts of the Moscow area (Moscow and the Moscow region) for investment in housing under construction reflects an expert assessment by 22 indicators, among which, along with price trends, factors of comfort and prestige, the environment plays an important role. Among the sample of cities in the Moscow region under consideration, there was not a single one corresponding to the indicator "extra clean".

In general, an unfavorable environmental situation is observed in the Moscow region: only 5 cities ( $18 \%$ of the market) meet the environmental standards "clean" or "sufficiently clean". The rest $(82 \%)$ are contaminated to some extent. More than a quarter of the considered territories are in a difficult ecological situation resulting from anthropogenic influence.

Undoubtedly, in the complex ecological and economic impact of construction on the environment, conditions for life and business are formed. "The quality of life of people, its comfort are determined not only by the amount of material wealth,"-notesM.Ya. Lemeshev [7], - "but also the quality of the environment in which people and living organisms live, i.e. the quality of the natural environment in which they have to live, work and rest". 
Nowadays, there are about 145 waste disposal facilities in the Moscow region, among which the most common are landfills of medium environmental hazard with a mixed composition of small and medium waste stored in a sand pit, as well as in a sand pit with a fill. Man-made massifs of solid waste are anthropogenic new formations and, at the same time, bodies obeying natural laws. These are evolving objects that, during an infinitely long life cycle, have a complex effect on the environment during operation and after the closure of objects.

In order to identify significant environmental factors included in the meta-infrastructure of the formation of the value of the structure, we will give a qualitative description of the physical and mechanical state of the solid waste landfill and consider the complex of physical and mechanical environmental parameters. The technogenic massif is a complex, heterogeneous, isotropic cohesive free-flowing medium that has a high mechanical structural cohesion due to fibrous fractions and adhesion due to the presence of wet sticky components. In addition, the material has properties such as caking, plasticity, and toughness. In the nomenclature of loose bodies, the technogenic massif of solid waste can be attributed to coherent loose bodies, which are close in their properties to solids and continuous media. Thus, in the study of the system "solid waste landfill - environment", the general mechanical equations of continuum mechanics are valid, taking into account the behavior of the material of the technogenic massif, i.e. its law of deformation, the criterion of plasticity and boundary conditions.

In many scientific works devoted to the search for ways to develop innovative construction and its adaptation to modern economic conditions, ecological construction acts as the object of research, which can be considered the basic area of development of the system "construction - living environment" $[8,9,10,11,12,13$, and others $]$.

Ecological housing construction can be defined as a set of relationships between subjects of the investment and construction sector in the production, distribution, exchange and consumption of ecological housing, non-residential ecological buildings and structures - any objects of ecological construction - and the formation of the ecological world outlook of society.

Ecological housing construction has a comprehensive goal - to maintain or improve the quality of objects and the comfort of their internal environment, to reduce the consumption of energy and material resources throughout the entire life cycle of the object. It is the creation of a comfortable living environment for people, and not just separate high-quality buildings, that is the main target vector of ecological construction. The main component of this vector is to reduce the overall impact of the facility on the environment and human health with the expansion and addition of systemic categories of economy, utility, durability and comfort. An assessment of environmental efficiency in relation to certain areas of ecological construction (Table 2) was presented by V.F. Sidorenko [9].

Table 2. General assessment of the components of ecological construction

\begin{tabular}{|l|c|l|}
\hline \multicolumn{1}{|c|}{ Areas } & $\begin{array}{c}\text { Score } \\
\text { point }\end{array}$ & \multicolumn{1}{|c|}{ Implementation stage } \\
\hline 1. Alternative energy & 3 & $\begin{array}{l}\text { urban planning facility, } \\
\text { village, house }\end{array}$ \\
\hline 2. Water treatment systems & 2 & $\begin{array}{l}\text { urban planning facility, } \\
\text { village, house }\end{array}$ \\
\hline 3. Environmental building materials & 2 & house \\
\hline 4. Saving energy, resources & 4 & house \\
\hline 5. Increased comfort & 6 & facility, house \\
\hline 6. Landscaping of the territory & 2 & house \\
\hline 7. Complex of components & $\geq 16$ & urban planning facility \\
\hline
\end{tabular}


The study of the theoretical foundations and research results of domestic and foreign scientists in the field of ecological construction $[8,9,10,11,12,13$, etc.] allows systematically considering the economic essence and prospects of ecological construction in the following aspects:

- ecological construction entails saving resources without increasing the amount of energy and materials involved in construction;

- the development of ecological construction leads to a decrease in environmental damage as a result of reducing the load on the environment and improving the quality of life of the population;

- ecological construction leads to the saving of energy, water and other resources due to energy efficiency, water saving, low waste, which together will have a positive effect on the economy;

- the formation of an ecologically rational world outlook of the population will lead to an acceleration in the rates of economic growth and the development of an innovative economy.

It should be emphasized that the modern period of housing construction in Russia and foreign countries is characterized by an increase in the influence of environmental factors. However, at present, the intensity of ecological construction in developed foreign countries is much higher than in Russia. The reasons for this situation are: the ambiguity of the conceptual-categorical apparatus and regulations in the field of ecological construction [14]; lack of assessment methods and criterion characteristics of environmental friendliness of buildings; lack of an effective system of state management of ecological construction; low awareness and incomplete understanding of the essence of eco-approaches, even by specialists; the mentality of unlimited and irresponsible use of almost free resources; business focus on maximum and quick profit; lack of interest of officials in innovations and progressive approaches.

There are clear prerequisites and positive precedents for the development of ecological construction at all levels of Russian society. For example, on 01.03.2013, the State Standard for Assessing the Compliance of Real Estate with Environmental Requirements came into force. This document regulates the use in construction practice of materials that have a minimal impact on the environment, the requirements for economical use of water and the mandatory disposal of construction waste. The Government of the Russian Federation adopted the Climate Doctrine of Russia, announced the application of environmental standards in the design and construction of facilities for the Skolkovo IC, arenas of the 2018 World Cup, etc.

Prospects for the development of ecological housing construction should be considered in a complex of areas such as: improving the environmental friendliness of building materials, the development of building ecology, the introduction of innovative environmental technologies, ecovillages, the development of recreational areas, etc. For example, one of the areas for the development of ecological construction is the global allRussian modern trend in housing construction - the reorientation to the low-rise housing market.

The urban planning concept, which has been at the forefront in Russia for many years, provided for the development of multi-storey housing construction, which led to an increase in the territorial density of the population, a decrease in comfort and environmental friendliness. In this regard, the relevance of alternative scientific and practical research and development aimed at the formation and development of low-rise residential buildings using industrial technologies and environmentally friendly building materials is increasing.

Today, a fundamental change has become a change in the basic criteria that determine the investment attractiveness, economic efficiency of construction. Operational cost metrics are critical compared to traditional construction estimates and return on investment. In this 
case, environmental friendliness as an approach at different stages of the life cycle of a real estate object acts as a significant economic factor in the investment attractiveness and development of the construction and development business.

In order to objectively assess the investment attractiveness of ecological construction, two strategies for allocating capital costs for the greening of construction projects are relevant. The first strategy is to keep the additional costs associated with sustainability to a minimum, since it reflects the interests of investors building a house for sale and not planning to participate in further operation. The overall greening in this strategy is realized by maximizing investments at the beginning of the construction process during the design phase. For example, the use of an integrated design approach can improve the energy efficiency of a building by reducing heating and ventilation capacity.

For investors-developers planning to further exploit real estate, a rational strategy is to increase capital costs in order to minimize operating costs in the long term. This approach involves considering the full life cycle of a building, assessing investments in green construction and their return on investment during the operational period.

The life cycle assessment of a building should include operating costs, renovation and capital repair costs, and the demolition or reconstruction of the building at the end of the life cycle. The operating costs of a building can be calculated based on the amount of resources consumed. In some cases, hidden costs and intangible benefits represent a powerful justification for investing in ecological (green) construction.

The choice of the investment object is influenced by both economic and non-economic factors, which are often not amenable to cost estimation, the calculation of which is a complex procedure. This statement is true for all levels and subjects of assessing investment attractiveness, since the investment goals at any level of assessment are dual. One of them is to ensure the return on investment. The second prevailing goal may be the achievement of a social, environmental or other effect. Investment attractiveness, accordingly, should reflect the overall possibility of achieving these goals.

According to international experts (CBRE, Steven Winter Associates, Davis Langdon, RICS), the average increase in the cost of building an ecological office building is $4-8 \%$, a maximum of $18 \%$ for the most complex projects. However, there are a large number of buildings with unique environmental characteristics built at the price of their "non-green" counterparts. According to research by the California Sustainable Building Working Group (2003), an additional $2 \%$ investment in building costs can result in savings of up to ten times the initial investment over the life of a project.

The added value of sustainable buildings consists of:

- reducing operating costs and repair costs;

- reducing risks during construction and operation;

- possible increase in the cost of prices or rent;

- attracting innovative schemes and additional sources of financing;

- additional PR and marketing advantages, a positive attitude on the part of local and federal authorities to the subjects of ecological construction.

The synergistic effect manifests itself when environmental, economic, technological and other effects complement and reinforce each other, create a common effect that is many times quantitatively and qualitatively superior to the effect of each of the factors involved in the economic process. The indicators of the quality of ecological construction, as a set of properties and characteristics ensuring the satisfaction of the needs and interests of various subjects, allow generalizing the complex of dissimilar factors affecting the attractiveness. Reducing this relationship to a mathematical relationship, we get:

$$
\mathrm{IA}=\mathrm{f}(\mathrm{E}, \mathrm{Q})
$$

Where $I A$ - indicator of investment attractiveness of ecological construction; 
$E$ - ecological construction efficiency;

$Q-$ ecological construction quality.

\section{Conclusions}

1. The development of ecological construction in Russia is currently progressing at an insufficiently high rate, which is primarily caused by the lack of effective systemic support from the state at the legislative and executive levels. Without a legislative framework and government support, any attempts to build with the introduction of innovative environmental solutions will not give the expected effect. There is a need for state incentives for economic entities in the real estate market, the creation of legal and economic mechanisms that will be the engine of ecological construction in Russia.

2. A green approach to building architecture can reduce capital costs, for example, optimizing air conditioning systems as a result of sustainable design can help reduce engineering costs and free up additional floor space. Reducing capital costs associated with, for example, energy efficiency, can recoup the environmental investment by reducing the need for additional energy capacity and hence the connection costs.

3. Prospects for the development of ecological housing construction should be considered in a complex of areas such as: improving the environmental friendliness of building materials, the development of building ecology, the introduction of innovative environmental technologies, ecovillage, the development of recreational areas, etc.For example, one of the areas for the development of ecological construction is the global allRussian modern trend in housing construction - the reorientation to the low-rise housing market. The urban planning concept, which has occupied a leading position in Russia for many years, provided for the development of multi-storey housing construction, which led to an increase in the territorial population density, a decrease in comfort and environmental friendliness. In this regard, the relevance of alternative scientific and practical research focused on the formation and development of low-rise residential buildings using industrial technologies and environmentally friendly building materials is increasing.

\section{References}

1. G.V. Averin, A.V. Zvyagintsev, E.G. Averin, Methods of system dynamics in the analysis of socio-economic development of countries and regions (DonNACEA, 2008).

2. Guidelines for the application of environmental indicators in Eastern Europe, the Caucasus and Central Asia (Geneva, 2006).

3. World Bank, World Development Indicators (issued annually) [Electronic resource]: http://www.worldbank.org/.

4. A.N. Larionov, T.G. Klyueva, Eco-friendly housing construction management: regional aspect: monograph (Moscow, Research Center "Strategy", 2010).

5. A.N. Larionov, M.Yu. Mishlanova, Development of the ecological and economic system "construction - living environment": monograph; Ministry of Education and Science of the RF, (Moscow, MGSU,2014).

6. V.P. Knyazeva, Ecology. Fundamentals of restoration (Moscow, 2005).

7. M.Ya. Lemeshev, M. Strategy for restoring the viability of Russia (towards the development of Russian civilization in the 21st century)(Moscow, Science-BusinessParity, 2013).

8. S.A. Erokhina, Methodological approaches to the formation and development of programs for ecological housing construction (Saint Petersberg, 2006). 
9. V.F. Sidorenko, Theoretical and methodological foundations of ecological construction: monograph (Volgograd State University of Architecture and Civil Engineering, Volgograd, 2000).

10. G. Imz, M. Ali, E. Burganova, A. Kondich, S. Madaminov, High technology buildings, (2014). http://www.rugbc.org/assets/files/3158/original/Ecodom.pdf.

11. M. Bauer, P. Mosle, Green Building. Guidebook for Sustainable Architecture (Springer, 2009).

12. H. Henderson,Becoming a green building professional (Wiley, 2012)

13. L. R. Brown, Eco-Economy: Building an Economy for the Earth (New-York, London, W. W. Norton \& Co., 2001)

14. L. Karieva, A. Akhmetshina, A. Mottaeva, E3S Web of Conferences 217, 07008 (2020). https://doi.org/10.1051/e3sconf/202021707008

15. Criteria for assessing the ecological situation of territories to identify zones of an ecological emergency and zones of ecological disaster: approved by the Ministry of Natural Resources of the Russian Federation 30.11.1992 [Electronic resource]:http://docs.cntd.ru/document/901797511. 